\title{
Textbook Reliance: Traditional Curriculum Dependence Is Symptomatic of a Larger Educational Problem
}

\author{
Timothy Scott (Corresponding author) \\ Graduate School of Human Science, Assumption University \\ Hua Mak Campus, Bangkok 10240, Thailand \\ E-mail: timothyrscott@hotmail.com
}

Farhat N. Husain

Quality for Excellence for Education Consultancy, Kingdom of Bahrain

E-mail: farhatnajamhusain@gmail.com

Received: March 23, 2021 Accepted: April 13, 2021 Published: April 23, 2021

doi:10.5296/jei.v7i1.18447ＵRL: https://doi.org/10.5296/jei.v7i1.18447

\begin{abstract}
The complexities of adapting traditional educational courses to a virtual setting highlighted numerous inequalities within the current United States' K12 school system. Students in low socioeconomic communities have suffered a more significant academic slide in core competencies due to poor lesson integration, online learning fatigue, poor learning environments, and low technological proficiency. Policymakers, believing achievement gaps result from teaching performance, have argued for additional academic controls that promote rigorous standardized instruction to reduce existing achievement gaps. However, a state-mandated textbook-driven curriculum that prioritizes test-taking strategies will only exasperate previous educational deficiencies. As numerous schools face significant financial constraints, technological and resource investment is severally limited, and teacher professional development is marginalized. Without appropriate tools or skills to adapt curriculum, classes devolve into simple rote-learning of textbook content lacking any semblance of differentiated instruction. Students in impoverished communities disassociate with taught content as textbooks lack a multicultural presentation; thus they perceive school environments as unwelcoming and hostile towards their lived-experiences. Performance-based funding through high-stakes accountability further incentifies underfunded schools to abandon student-centric learning designs and prioritize a textbook dependent 'one-size-fits-few' strategy to avoid sanctions to meet state benchmarks. While a
\end{abstract}


return to traditional classroom instruction may signal a return to normal, without increased state funding, reduced emphasis on standardized testing, improved teacher professional development, and incorporation of multivoiced textbooks, a return to normal will additionally signal a return to existing educational inequalities in the US.

Keywords: K12, Textbook dependency, Education inequality, Standardized testing, High-stakes accountability

\section{Introduction}

State governments, districts, and schools are now confronting the complexities of student re-introduction into the physical classroom. Although institutions have engaged in numerous action plans at the start of the fall 2020 semester, the onslaught of outbreak waves has complicated returning to in-class instruction. As numerous states have repeatedly been forced back to the virtual environment through regional and state mandates to control spread, a cohesive transition strategy has yet to crystalize. With the roll-out of vaccines to combat the pandemic, Dr. Fauci, the Chief Medical Advisor to the President of the United States, cautiously outlined a return to relative normality by the end of fall 2021 through umbrella immunity (McPhillips, 2021). The targeted timeline allows superintendents and school administrators to develop full reintegration policies. Beyond students' and teachers' safety, schools must address the substantial academic slide resulting from the prolonged out-of-class instruction most students have experienced. Studies have approximated learning loss at 50\% for many young learners, indicating dramatic declines in retention and understanding of core subject content compared to traditional academic slides (Dorn et al., 2020; Kuhfeld \& Tarasawa, 2020; Kuhfeld et al., 2020). Concerned with pronounced achievement gaps and deficiencies in core knowledge, educational bodies have prioritized increased instructional standards and the utilization of updated textbook curriculum to address new post-covid academic demands (Cahapay, 2020; New Jersey Department of Education, 2020).

The problematic integration of forced online learning has propelled the idealization of a physical return to the classroom and the traditionalistic pedagogical approaches of pre-pandemic America. Inadequate training of instructors for online teaching (Pourreau \& Lokey-Vega, 2020), student learning fatigue (Labrague \& Ballad, 2020; Räisänen et al., 2020), environmental limitations (Johnson et al., 2020), and parental pressure (Lau \& Lee, 2020) have exasperated an existing onerous situation of learning and teaching in the virtual classroom. These issues have brought a nostalgic revival of increased standardization and adherence to state-designated textbooks to offset present academic declines. The desire to embrace previous norms to escape current hardships will shackle learning to set curriculum, effectively inhibiting students' educational growth. Textbook dependency is a by-product of current educational conditions in the K12 system, acting as a precursor in the decrease in teacher-efficacy in the online classroom. Schools were overwhelmed by budgetary shortfalls pre-pandemic, reducing district leadership's ability to provide professional development training to teachers on utilizing outside resources, an issue only to get worse post-pandemic (Atchison, 2020). Without the appropriate skills, teachers are incapable of adapting the material to meet current student needs. Strict course agendas, increased standardization, and 
additional external oversight will further reduce teacher curriculum engagement, impacting overall classroom agency. The return to a textbook-driven classroom will be reinforced by returning to state-mandated summative assessment, emphasizing quantifiable evaluation; thus, reducing concepts and situations to a single-voiced resource.

The authors believe that a return to previous classroom norms accentuated by focused textbook curriculum will only intensify prevailing educational deficiencies. Over-reliance on textbooks in classes results from inadequate educational funding, suffocating external policies stifling teachers' roles as classroom authorities and agents of change, and the diminished real-world student preparation through a single-voiced situational account in a multi-voiced and multi-dimensioned climate. This paper highlights that while textbooks may bring a form of normality to the learning environment, the dependency on a single resource underscores systemic issues festering under the textbook reliance problem.

\section{Financial Constraints}

The public education sector depends on the allocation of government funds to maintain operations, with most school board budgets connected to community tax collection. Thus, economic downturns and resulting declines in tax revenue directly impact the viability of in-class investment. As communities continue to be economically devastated by the pandemic, state legislatures have begun to enact educational support bills to stem current shortfalls. However, near-future initiatives will not solve pre-existing conditions in many regions that stifled administrators' capacity to distribute financial resources to in-need academic areas like classroom technology and teacher professional development. Declining community solvency and regional income discrepancies have directly contributed to declines in student achievements (Owens et al., 2016; Strange, 2003) before the pandemic, and will continue to impact institutional stability post-pandemic. School administrators are tasked with allocating resources in a 'maximin' strategy, where they attempt to identify actions that have the least financial risk. By maximizing certainty with selecting methodologies via risk-avoidance, administrators prioritize established principles and educational pedagogical approaches in the classroom over technological integration or realignment of teaching strategies. Textbooks approved by state oversight bodies are considered the safe, cost-effective instruction method, as it requires limited investment and instructor pre-course training to achieve modest academic goals and state benchmarks.

Traditional textbook reliance fosters stagnation in the classroom, limiting teacher methodology options due to insufficient capital overlay on classroom technology. Studies by De Los Arcos et al. (2016), Mason and Kimmons (2018), and McGee et al. (2018) all have indicated integration of e-resources and technology in the physical learning environment are positively correlated with student engagement, in-class interaction, and instructors' ability to personalize instruction. However, schools are resistant to change, interpreting technology as an add-on tool rather than a new approach. Large scale classes in the public school sector, coupled with limited computer access, poor user interface (McGee et al., 2018), inadequate support, and costs beyond physical hardware (Ireh, 2010), are driving factors for maintaining academic status-quo. While technological engagement outside the classroom is pronounced 
with the proliferation of smartphones and tablets, the socioeconomic disparity in urban and rural settings diminishes out-of-class expectations and deprioritize school-oriented technological engagement. By maintaining existing learning strategies and continuing an educational culture reliant on textbooks, students do not have to purchase additional resources, school leaders can maintain program conformity, and teachers can persist with pedagogical approaches deemed comfortable.

Teacher insecurity with modifying existing classroom approaches is a significant factor impeding investment in curriculum development. Comfort level with classroom technology is a significant factor, as teachers may have difficulty envisioning the benefits of integrating technology into their current teaching strategy. Kopcha (2012) found that demanding teaching schedules complicated the time for training, and the required focus necessary for teachers to become comfortable with new tools, creates barriers of hesitation. The ever-changing technological landscape further entrenches teacher apprehension, as teachers feel they lack control over the technology (Badri et al., 2014). Pressures to adapt without support overwhelm teachers, creating change fatigue (Kopcha, 2012; Orlando, 2014) and eventual ambivalence and tentativeness of potential gains compared with traditional methodologies espousing textbook usage. Teachers feel more in control with textbooks (Orlando, 2014), as they prioritize mastery of content through repetition and understanding. The quality of instruction impacts learning outcomes; however, student intrinsic and extrinsic motivations are additionally correlated with pedagogical approaches that students perceive as meeting their future needs (Mason \& Kimmons, 2018; McGee et al., 2018). The need for technological knowledge in today's workforce drives students to incorporate and demand better technological assimilation in the classroom. By prioritizing professional development, the school can refine teacher technological proficiency and improve self-efficacy.

Teacher professional development is critical in providing opportunities for teachers to strengthen their knowledge of up-to-date instructional strategies to effectively manage, communicate, and lead students in their learning. Continuous, high-quality training, mentoring, and support directly affect teacher motivation, teacher agency, teacher retention, and student achievement (Bishop, 2016). Unfortunately, school districts that suffer severe financial shortfalls allocate what little training budget available towards general issues like assessing students and following preconceived textbooks according to state testing. Teachers are not provided a range of professional development courses that expand on the necessary skills to engage and maintain effective classrooms, resulting in significant teacher turnover. Schools in lower socioeconomic communities or those with large numbers of under-performing students are overwhelmed with financial limitations (Katz, 2018). As issues persist, administrators relegate technology and skill development as expensive luxuries instead pushing for a standardized approach to promote conformity to meet state mandates. Textbooks ensure conformity and reduce training provision; teachers are increasingly expected to be generalists, not specialists or authoritative figures on core subject matter; teachers merely follow pre-designed steps created by external sources (Scott, 2021). While this reduces administrative stress, it amplifies the academic learning gap between districts and impairs teachers' ability to conduct practical courses. The increase in technology 
investment through national and state grants continue to be underutilized in numerous schools as the districts cannot maintain the equipment or provide the required training to effectively transition away from textbooks and towards a technological adaptive learning environment

\section{External Constraints}

Researchers and academics clamor for an increase in student-centric inquiry-based differentiated learning methodology within the public school system, idolizing a curriculum that strives for discussions that are adaptive for both student and community needs. Research continuously indicates significant correlations with teacher engagement in curriculum design and school decision-making process with teacher motivation, efficacy (Brezicha et al., 2020; Demir, 2020), leadership (Handler, 2010; Leithwood \& Jantzi, 2000), and student outcome (Dolenc \& Kazanis, 2020; Handler, 2010; Kopcha, 2012). However, the continuous enactment and expansion of both state and national educational policies like the No Child Left Behind, Race to the Top with Common Core, and the short-lived Patriotic Education Act removes the emphasis on community-specific and student-centric strategies. While proponents argue a standardized national curriculum will usher dramatic improvements to classroom quality, student testing and eliminate achievement gaps (Bleiberg \& West, 2014), reforms effectively prioritizing a singular-voice representation of content to maximize quantifiable comparisons that peg test results to knowledge and instructor competency.

Through mandated curriculum standards and the prioritization of selected textbooks, the external control of curriculum presentation reduces teachers' capabilities to engage with the material and adapt it toward their students' needs. As legislators and publishers dictate what is required in the classroom, those constructs' appropriateness is drawn into question. As required qualities or understanding lacks consensus, the creation of material is subjectively broad and generally inadequate. With curriculum development originating at the state level, content inclusion may adopt a persuasive political ideology that aligns with governing officials, reducing a balanced multi-perspective presentation. This issue is not asserting teachers are free of bias or political motivations; however, the massification of singular content that limits multiple perspectives has pronounced long-term ramifications. An exposé by Goldstein (2020) identified stark differences in history textbooks produced by the same publisher but aligning with different state mandates. Californian books placed considerable emphasis on the impacts of slavery, the creation of the Bill of Rights, and the necessity of gun control regulations; alternatively, textbooks in Texas place significantly less emphasis on slavery and the drafting of the Bill of Rights and avoids mentioning gun control legislation (Goldstein, 2020). The lack of contrasting ideological stances, rationale, or debate in the presentation of facts within textbooks, complicates the classroom experience. Teachers are expected to promote a range of opinions that challenge students to engage with the content and form educated opinions (Alghamdi, 2017); however, the limitation of resources and the diminishing of counter-arguments in many textbooks make this task exponentially arduous.

Teacher efficacy has been challenged with diminished curriculum design roles, as professional competency is aligned with disseminating textbook content to meet pre-designed objectives. Although students' pace varies immensely in large classes, mandated curriculum 
standards demand content to be taught and learned by a specific deadline. Adapting textbooks to student learning needs, expanding on the information presented, or including supplementary material becomes overwhelmingly difficult. Curriculum and their appointed textbooks seek to improve performance through more rigorous standards; yet the content demands are often excessive and fail to meet many students' needs (Troia et al., 2016). Disparaged, teachers decrease their efforts to engage material and present information 'as-is' to ensure content is covered (Demir, 2020). Teachers also face stark ethical dilemmas when determining resource focus and engagement. By prioritizing textbooks, student achievement on standardized testing may improve, resulting in better higher educational opportunities. However, presenting single-sided perspectives or information that have apparent gaps in its construct reduces the accuracy of the information learned and may bias student conceptual understanding of situations. Financial consideration can further complicate teachers' moral paradox, as schools and parents spend considerable amounts of money on textbooks with the expectation of them being fully utilized (Wu, 2019). Teachers are confronted with choices that leave a moral residual, impacting long-term performance (Scott, 2021). By conforming to organizational designs, teachers may achieve higher student results and personal assessment reviews; but reduce their in-class agency and defer their authority position to the assigned textbook.

\section{Assessment Constraints}

The development and implementation of an appropriate and effective assessment strategy that aligns with textbooks has always been a contentious issue among educational stakeholders. Determining the method that accurately records what a student has learned is problematic as numerous internal and external factors impact assessment. Students may not understand the topics or objectives of assignments; they may have issues with writing papers or get flustered with multiple choice questions; they may lose interest due to pace or become distracted. The abrupt shift to online classes intensified numerous external factors that diminish summative assessment results, complicating an already complex issue. School boards and policymakers de-emphasized summative assessments and focused primarily on formative methods as tests were designed for physical settings. Institutions additionally lacked the ability for large scale roll-out of alternative testing mechanisms and accompanying designed textbooks. With the reduced emphasis on summative assessment, Husain's (2021) analysis of graduating students' academic outcomes determined results were significantly higher than previously pre-pandemic student achievements in core subjects, raising questions about the reliability of set curriculum and testing as an indicator of learned knowledge. With the canceling of SAT and ACTs, universities have re-analyzed the value of standardized testing as a predictor of higher education success. However, state policymakers argue the necessity of standardized assessment, as it is an effective mechanism for accountability in the compliance by schools and teachers meeting grade-standards set by the state (Connecticut State Department of Education, 2020).

The inclination for teachers, schools, and state education departments to examine the effectiveness of content and methodology toward student knowledge actualization is rational, as it allows for the adaption of tools to best serve the students' needs. With the further 
expansion of state involvement in the development of curriculum and emphasis on annual standardized testing, the examination of student achievement results focuses less on attributes of the content delivered but on the ability teachers have transferring pre-designed content. Standardized testing is devised as a tool of oversight, with the assumption that public education institutions should be held accountable to all stakeholders; however, with schools and teachers more knowledgeable on the various facets involved in the classroom, external controls may misrepresent elements in the examination process (Hamilton et al., 2002). The politicization of the term accountability shifted standardization from a low-stake student-oriented incentifying mechanism to a high-stake tool with threats of penalty through reductions in school funding, sanctions against schools, or potential institutional de-accreditation (Graue \& Johnson, 2011). With textbooks specifically designed to achieve state mandates for a standardized test, instructors are not evaluated by their ability to spark student engagement, prioritize learning needs, or personalize information for more profound understanding, but rather the skill of presenting content as written by determined deadlines. Maslovaty and Kuzi (2002) argued that performance-based funding is antithetical, superficially espousing student achievement growth but primarily motivated in controlling the presentation of information and the associated tools through the threat of negative consequences. With the implementation of performance-based funding in 41 states, administrators are obligated to assess teachers' instruction, ensuring their methodology conforms to state standards, not necessarily student needs, ultimately expanding academic learning disparity in many in-need communities (Ortagus et al., 2020).

Test-oriented accountability advocates contend that pre-existing achievement gaps were a condition of educational institutions' inability to teach quality lessons due to educator lethargy and reliance on out-of-date lesson plans. Implementing rigid control of textbooks and curriculum design counters existing institutional flaws and improve across-the-board student achievement (Hamilton et al., 2002). However, without appropriate funding to reduce the capacity gaps, performance-based funding shifts educational focus from student-oriented to fund-generation, especially in lower socioeconomic communities. The quantifiable nature of standardized testing and set textbooks reallocates focus to numbers rather than needs and value. As funding is directly related to externally designed benchmarks of achievement, instruction invariably deviates from group learning to areas that best maximize potential outcomes.

In underfunded schools, teachers present the assigned textbook content but prioritize assistance to 'bubble kids.' Bubble kids are students just below the threshold of passing standardized national testing (Booher-Jennings, 2005). As low performing schools are desperate for funding, administrators pressure teachers to focus on children slightly below achievement goals to ensure minimum standards are met, and funding is received (Koretz, 2008). While these small groups of children receive additional support to improve their overall standard, other students are left with little guidance beyond basic instruction. Standardized testing and their affiliated textbooks systematically widen the achievement gap; quality of education declines due to those most at risk being ignored or marginally supported because textbooks do not meet their needs, and schools are primarily focused on funding 
strategies. The basic tenet of standardized testing is that everyone is provided the same questions, the same textbooks, the same evaluation, and have the same opportunities to succeed; however, environmental and capacity differences ensure those students in lower socioeconomic regions and students of color face immense inequality in their opportunities to succeed.

Since the onset of No Child Left Behind, Smith (2006) noted a disproportionate number of students of color have failed to graduate, with large dropout concentrations in poverty-stricken neighborhoods across the United States. Large class size and reduced personal attention are significant factors impacting these lower socioeconomic communities; however, textbooks' structural inequality further demotivates at-risk students. As numerous textbooks prioritize singular views, the content lacks a multicultural perspective that resonates with students of color. Many communities refer to assigned textbooks as 'one-size-fits-few,' attributing the content to align particularly with white middle to upper-class Americans opposed to the diverse community within a medium to large scale urban setting (Bondie et al., 2019); prioritizing the assimilation of beliefs to a singular perspective. Students of lower socioeconomic standing, students of color, and other minorities are additionally prone to maladaptive behavior in the classroom, triggered by inadequate teacher interaction and disassociation with textbook content (Oostdam et al., 2018); students perceive the learning environment as hostile. Schools in lower economic communities are substantially less likely to dissuade students from exiting their studies, as school average improves with their exclusion; thus, the institution is more likely to avoid sanctions by state education departments (Andrepoint, n.d.). The continuous bombardment of negative narratives conveying students within low-performing schools as academically inadequate facilitates a psychological acceptance of diminished worth, increasing the likelihood of lower performance. 'Stereotype threat' is another factor that perpetuates inequality in the classroom (Steele, 1997), reaffirming to many individuals that a standard textbook is not designed for them and state testing is designed for them to fail.

\section{Recommendations}

Combating the educational system's deficiencies is a long-term multi-procedure undertaking that would undoubtedly vary from state to state and community to community. Middle-class suburban schools may currently thrive under the existing conditions and have little incentive to aggressively promote change, while urban or rural schools lack the significant financial capacities of those suburban schools and strongly advocate change. These recommendations are not meant to offer easy fixes to existing problems, but to promote active discussions to improve in-need communities' current situations while minimizing the risk to institutions currently exceeding expectations.

\subsection{Financial}

The financial disparity between communities is a major underlying factor impacting school progress and student achievement. Many teachers lack the equipment, training, and flexibility to offer differential instruction for their students. With many classes only equipped with a single textbook, classes rarely engage the material content beyond rote-learning for 
test-taking strategies. By improving the economic conditions within these schools, opportunities in the classroom will significantly improve. The state and national governments need to take a stronger position in reducing schools' economic disparity, especially with the political posturing of school accountability regarding student performance. The government needs to increase financial grants to schools to ensure minimum equipment and technology availability, including updating and maintenance. Grants should be provided with fixed school allocation requirements and audits to ensure a minimum number of computers per active student and a minimum number of classroom resources (projectors and monitors).

The government must prioritize opportunities for teachers (and school leaders) to be provided with appropriate professional development courses. The offering of a wide range of programs will assist teacher skill development, instruction techniques, resource incorporation, student support, and technical proficiency, especially for schools in lower socioeconomic communities. Improvements in teacher instruction methodology and technical proficiency will reduce textbook dependency and improve student-centric learning opportunities. With teacher shortages, especially in STEM fields, the state and the national government must provide financial and professional incentive programs to recruit and retain qualified teachers in low-performing or low socioeconomic communities. Increased salaries, education grants, and relocation support are examples of various incentive programs being used in middle-class communities with success. With financial assistance or partial coverage of teacher salaries in communities with solvency issues, many communities can reduce instructor turnover and provide stable quality learning opportunities for their students.

\subsection{External}

The elimination of barriers associated with external constraints is often connected to political considerations; thus, they are problematic in their revision or removal from government strategies. State and national curriculum programs were designed and passed by legislative bodies, appealing to the larger population and marginalizing the communities that these policies impact significantly. While financial considerations will amend many difficulties facing numerous communities, fundamental policy reforms need to occur to achieve long-term stability and equality. The development of textbooks and corresponding curriculum demands by central government bodies may create a level of conformity that simplifies cross-evaluation; however, the subjective nature of selecting what is best ensures many voices are silent. To appeal to all communities, curriculum must improve the multicultural presentation of topics to improve the content engagement opportunities. Aligning school course development with state-mandated instruction policies would be complicated but not impossible. State regulators can reduce the content control to a specific number of topics per subject, reducing the time required to cover testable sections. Teachers and schools can then develop supplemental or community-oriented topics that engage with the students' lived experience while still providing state tests' focused instruction.

Empowerment will improve teacher efficacy with their improved roles of agents of change, increasing motivation and classroom discussions. Training and supervision would be required, merely shifting the decision-making process back to the instructor without the tools or skills 
will create additional hardships. Pre-service and pre-program training coupled with trained supervision and mentorship will provide teachers with the necessary skills to engage the curriculum, select the appropriate resources, and incorporate supplemental material with government-assigned curriculum content. To reduce the focus on a singular textbook or designed curriculum, e-resources should be promoted and incorporated into the instruction process. Fusing e-resource content will reduce the politicization of content in the classroom, allowing for better nonpartisan presentation of topics. The government needs to provide financial support for lower socioeconomic status families to ensure internet connectivity, providing access to online tools and resources to build their learning capacity. Providing an improved connection to in-need communities would reduce reliance on a textbook, improving resource availability and instruction flexibility in the classroom as students can access and participate in more discussions. With government assistance, schools can better integrate e-books and resources in their curriculum, reducing the costs of purchasing physical books by both parents and schools.

\subsection{Assessment}

The high-stakes strategies promoting schools and teachers' accountability have had significant impacts on underfunded schools, especially in communities that students of color primarily represent. The fear of sanctions and the need for government subsidies to offset financial gaps has caused the prioritization of bubble students. Larger numbers of minorities and students of color are marginalized in the classroom as teachers strive to meet the state's benchmarks, ultimately creating a perceived hostile environment. While still accountable under state regulations, middle-class and economically stable schools are less concerned about government support as community tax can provide the necessary funding for their operations. As numerous studies identify high-stake accountability as a primary factor impacting minority students' academic growth, a complete reconceptualization needs to occur. While schools should remain accountable to ensure their student success, these measures should not be the factor leading to further inequality in the United States of America.

Accountability measures need to incorporate a more specialized evaluation method, including a more robust community understanding of cultural, economic, and social factors unique in many areas. The creation of education assessment teams to interact and work directly with the schools and teachers would better understand the various conditions within those learning environments. Assessment teams can provide additional training, observation, and support needed in struggling schools, providing clear directions without the constant fear of sanction. Assessment teams can also identify factors impacting academic declines and student retention otherwise not present in nationalized testing indicators. The reduction of negative re-enforcement and increased collective understanding will promote growth and eventual self-reliance. Students in lower socioeconomic communities, especially students of color, need to be offered the same opportunities as wealthier communities.

As schools start to be assessed through alternative non-testing methods, standardized testing and textbook reliance should diminish. Increased priority on teacher engagement in 
curriculum development, decreased focus on selected bubble students, and increased financial classroom investment, ultimately promotes equality for all students. Providing assessment on classroom performance instead of standardized testing will further promote growth over conformity. While students with current achievement gaps will continue to struggle, by removing the psychological pressure of standardized exams and promoting appropriate curriculum, many students' stereotype threat will ease. Achievement gaps will not be eliminated immediately; however, positive growth will motivate and encourage students that currently feel marginalized and voiceless. The diminished focus on standardized exams will free teachers from their textbook shackles and allow for differential learning opportunities that focus on the student's need, not the exam's need.

\section{Conclusion}

Adapting instruction methods and striving to connect with students by imparting the necessary knowledge and intellectual skills to facilitate advancement in higher education and the workforce, are core tenets of government education policies. The introduction of strict high-stake accountability measures through state and national curriculum diminishes education equality, creating systematic declines in the educational process in many low socioeconomic communities. Although a significant hindrance in the classroom, textbook dependency is a condition of numerous underlying factors that are at the root of glaring educational gaps across the US. Financial disparities between school boards and regions account for a pronounced differential standard in the quality of education taught. Communities with solvency issues invest considerably less in teachers' professional development and resource allocation for class instruction. Unequipped to personalize information, teachers in many communities rely entirely on a single information source, state-designed textbooks, to foster learning in their classroom. Engagement suffers without differential instruction, as a one-size-fits-all approach lacks a multi-dimensional presentation needed to embrace the complexities of lived experiences in many communities. Low equipment standards reduce cross-instrument incorporation, further reducing student and teacher capacities to navigate growing demands for technological proficiency required in today's educational environment.

Teacher efficacy is dramatically lower in impoverished communities, impacting motivation and classroom participation. Increasing numbers of teachers no longer consider themselves agents of change, unable to promote their classrooms' desired educational growth. Students feel marginalized through the representation of the content in the textbooks and the quality of instruction they receive. The bombardment of negativity has immense psychological impacts on students, often resulting in hostility and aggression. Underfunded schools and overworked teachers cannot cope, increasing the number of students who drop out or fail and teachers leaving the profession. The incorporation of state mandates on student learning increases the pressure on an already taxed educational system, leading many low-performing schools to embrace education-for-the-few instead of the intended education-for-all policy initiative. Teachers focus on borderline students to ensure benchmarks are met to avoid sanction, further marginalizing students most in need. The cyclical nature of oppressing large groups through set textbooks, standardized tests, reduced financial support, and increased risk of 
sanction ensure an expansion of education and achievement gaps. Without providing the appropriate financial and educational resources, yet demanding assimilation and compliance, issues will continue to fester.

Policymakers, school administrators, and teachers need to prioritize the need of the students over politicalized mandates. Either reducing or eliminating performance-based funding and increasing state and national financial support to under-equipped, under-trained, understaffed schools will do significantly more than the demanding of benchmark achievements. State-wide professional development opportunities, minimum technological proficiency through training, and maintaining adequate equipment levels in every school will also spur improvements. Financial and professional incentive programs to recruit and retain qualified teachers in low-performing or low socioeconomic communities will promote instructional diversity and quality. State-supported salaries, signing and term-length bonuses, education grants, and relocation support are examples of various incentive programs being promoted and utilized in communities with success. States can also provide families of lower socioeconomic status basic internet connectivity, providing access to online tools and resources to build students' learning capacity further. Curriculum redesign and updating textbooks to incorporate a multicultural, multivoiced perspective will assist with engagement and improved dialogue in all schools. With upgraded school resources in low socioeconomic communities, integrating alternative textbooks or supplementary material will further personalize the curriculum. Reducing state-wide standardized testing would mitigate the stereotype threat many students suffer from, improving focus and academic performance. Summative assessment will still be necessary, but assessing content that is more reflective of conditions beyond a single group will simultaneously promote diversity and academic growth. The current state of the K12 education system is inadequate and rife with foreseen and unforeseen inequalities. The promotion of inclusive multicultural material and less dependency on pre-designed textbooks that reflect a single-voiced standardized test will improve overall student understanding and overall human capacity.

\section{References}

Alghamdi, Y. (2017). Multicultural education in the US: Current issues and suggestions for practical implementation. International Journal of Education, 9(2), 44-52. https://doi.org/ 10.5296/ije.v9i2.11316

Andrepoint, D. L. (n.d.). My place in America: Authentically representing multiethnic students in mainstream literature. Houston Teachers Institute, USA.

Atchison, D. (2020). COVID-19 and the squeeze on state education budgets. American Institutes for Research, USA.

Badri, M., Al Rashedi, A., Yang, G., Mohaidat, J., \& Al Hammadi, A. (2014). Technology readiness of school teachers: An empirical study of measurement and segmentation. Journal of Information Technology Education, 13, 257-275. https://doi.org/10.28945/2082

Bishop, M. J. (2016). The impact of ongoing professional development on math assessment. Carson-Newman University, USA. 
Bleiberg, J., \& West, D. (2014). In defense of the Common Core standards. Brooking's Center for Technology Innovation.

Bondie, R. S., Dahnke, C., \& Zusho, A. (2019). How does changing “one-size-fits-all” to differentiated instruction affect teaching? Review of Research in Education, 43, 336-362. https://doi.org/10.3102/0091732X18821130

Booher-Jennings, J. (2005). Below the bubble: "Educational triage" and the Texas accountability system. American Educational Research Journal, 42(5), 231-268. https://doi.org/10.3102/00028312042002231

Brezicha, K. F., Ikoma, S., Park, H., \& Le Tendre, G. K. (2020). The ownership preception gap: Exploring teacher job satisfaction and its relationship to teachers' and principals' perception of decision-making opportunities. International Journal of Leadership in Education, 23(4), 428-456. https://doi.org/10.1080/13603124.2018.1562098

Cahapay, M. B. (2020). Rethinking education in the new normal post-COVID-19 era: A curriculum studies perspective. Aquademia, 4(2). https://doi.org/10.29333/aquademia/8315

Connecticut State Department of Education. (2020). Sensible assessment practices for 2020-21 and beyond. Connecticut State Department of Education.

De Los Arcos, B., Farrow, R., Pitt, R., Weller, M., \& McAndrew, P. (2016). Adapting the curriculum: How K-12 teachers perceive the role of open education resources. Journal of Online Learning Research, 2(1), 23-40.

Demir, S. (2020). The role of self-efficacy in job-satisfaction, organizational commitment, motivation and job involvement. Eurasian Journal of Educational Research, 85, 205-224. https://doi.org/10.14689/ejer.2020.85.10

Dolenc, N. R., \& Kazanis, W. H. (2020). A potential for interest driven learning to enhance the inquiry based learning process. Science Educator, 27(2), 121-128.

Dorn, E., Hancock, B., Sarakatsannis, J., \& Viruleg, E. (2020). COVID-19 and student learning in the United States: the hurt could last a lifetime. McKinsey \& Company.

Goldstein, D. (2020). Two states. Eight textbooks. Two American stories. The New York Times. Retrieved from https://www.nytimes.com/interactive/2020/01/12/us/texas-vs-californ ia-history-textbooks.html

Graue, E., \& Johnson, E. (2011). Reclaiming assessment through accountability that is "just right”. Teacher College Record, 113(8), 1827-1862.

Hamilton, L. S., Stecher, B. M., \& Klein, S. P. (2002). Making sense of test-based accountability in education. RAND Corporation.

Handler, B. (2010). Teacher as curriculum leader: A consideration of the appropriateness of that role assignment to classroom-based practitioners. International Journal of Teacher Leadership, 3(3), 32-42. 
Husain, F. N. (2021). Use of digital assessment how to utilize digital Bloom to accommodate online learning and assessment? Asian Journal of Education and Training, 7(1), 30-35. https://doi.org/10.20448/journal.522.2021.71.30.35

Ireh, M. (2010). Budgeting and funding school technology: Essential considerations. School Business Affairs, 76(7), 18-22.

Johnson, M. W., Maitland, E., \& Torday, J. (2020). Covid-19 and the epigenetics of learning. Postdigital Science and Education, 3, 389-406. https://doi.org/10.1007/s42438-020-00190-9

Katz, V. (2018). Teacher retention: evidence to inform policy. EdPolicyWorks.

Kopcha, T. J. (2012). Teachers' preceptions of the barriers to technology integration and practices with technology under situated professional development. Computers \& Education, 59(4), 1109-1121. https://doi.org/10.1016/j.compedu.2012.05.014

Koretz, D. (2008). Measuring up. What educational testing really tells us. Cambridge, MA: Havard University Press. https://doi.org/10.2307/j.ctv1503gxj

Kuhfeld, M., \& Tarasawa, B. (2020). The COVID-19 slide: What summer learning loss can tell us about potential impact of school closure on student academic achievement. Educational Researcher, 49(8), 549-565. https://doi.org/10.3102/0013189X20965918

Kuhfeld, M., Tarasawa, B., Johnson, A., Ruzek, E., \& Lewis, K. (2020). Learning during COVID-19: Initial findings on students 'reading and math achievement and growth. NWEA.

Labrague, L. J., \& Ballad, C. A. (2020). Lockdown fatigue among college students during the COVID-19 pandemic: Predictive role of personal resilience, coping behaviours, and health. medRviv. https://doi.org/10.1101/2020.10.18.20213942

Lau, E. Y. H., \& Lee, K. (2020). Parents' views on young children's distance learning and screen time during COVID-19 class suspension in Hong Kong. Early Education and Development. https://doi.org/10.1080/10409289.2020.1843925

Leithwood, K., \& Jatzi, D. (2000). Principal and teacher leadership effects: A replication. School Leadership and Management, 20(4), 415-434. https://doi.org/10.1080/713696963

Maslovaty, N., \& Kuzi, E. (2002). Promoting motivational goals through alternative or traditional assessment. Studies in Educational Evaluation, 28(3), 199-222. https://doi.org/ 10.1016/S0191-491X(02)80002-5

Mason, S. L., \& Kimmons, R. (2018). Effects of open textbook adaption on teachers' open practices. International Review of Research in Open and Distributed Learning, 19(3), 128-150. https://doi.org/10.19173/irrodl.v19i3.3517

McGee, A., Del Campo, M. G., Smith, S., \& Myers, R. (2018). Replacing textbooks with video and state standards in the K-12 classroom. G7 Research.

McPhillips, D. (2021). This is how long it could take to vaccinate all the adults in the US against COVID-19. CNN. Retrieved from https://edition.cnn.com/2021/01/21/health/us- 
vaccination-timeline-analysis/index.html

New Jersey Department of Education. (2020). Summer learning resource guide 2020: State guidance for district and school leaders. New Jersey Department of Education.

Oostdam, R. J., Koerhuis, M. J. C., \& Fukkink, R. G. (2018). Maladaptive behavior in relation to the basic psychological needs of students in secondary education. European Journal of Psychology of Education, 34, 601-619. https://doi.org/10.1007/s10212-018-0397-6

Orlando, J. (2014). Veteran teachers and technology: Change fatigue and knowledge insecurity influence practice. Teachers and Teaching, 20(4), 427-439. https://doi.org/10.1080/ 13540602.2014 .881644

Ortagus, J. C., Kelchen, R., Rosinger, K., \& Voorhees, N. (2020). Performance-based funding American higher education: A systematic synthesis of the intended and unintended consequences. Educational Evaluation and Policy Analysis, 42(4), 520-550. https://doi.org/ $10.3102 / 0162373720953128$

Owens, A., Reardon, S. F., \& Jencks, C. (2016). Income segregation between schools and school districts. American Educational Research Journal, 53(4), 1159-1197. https://doi.org/ $10.3102 / 0002831216652722$

Pourreau, L., \& Lokey-Vega, A. (2020). Perceptions of K-12 online teaching endorsement program effectiveness in Georgia: a case study. Educational Planning, 27(2), 7-21.

Räisänen, M., Postareff, L., \& Lindblom-Ylänne, S. (2020). Students' experience of study-related exhaustion, regulation of learning, peer learning and peer support during university studies. European Journal of Psychology of Education. https://doi.org/10.1007/ s10212-020-00512-2

Scott, T. (2021). Higher education's marketization impact on EFL instructor moral stress, identity, and agency. English Language Teaching, 14(1), 99-106. https://doi.org/ 10.5539/elt.v14n1p99

Smith, R. (2006). Public education \& black male students: the 2006 state report card. Schott Foundation for Public Education.

Steele, C. (1997). A threat in the air: How stereotypes shape intellectual identity and performance. American Psychologist, 52(6), 613-629. https://doi.org/10.1037/0003-066X. 52.6 .613

Strange, M. (2003). Equitable and adequate funding for rural schools: Ensuring equal educational opportunities for all students. Nebraska Law Review, 82(1), 1-8.

Troia, G. A., Olinghouse, N. G., Wilson, J., Steward, K. A., Mo, Y., Hawkins, L., \& Kopke, R. A. (2016). The common core writing standard: A descriptive study of content and alignment with a sample of former state standards. Reading Horizons, 55(4), 98-141.

$\mathrm{Wu}, \mathrm{T}$. (2019). How professors help rip off students. The New York Times. Retrieved from https://www.nytimes.com/2019/12/11/opinion/textbook-prices-college.html 


\section{Copyright Disclaimer}

Copyright for this article is retained by the author(s), with first publication rights granted to the journal.

This is an open-access article distributed under the terms and conditions of the Creative Commons Attribution license (http://creativecommons.org/licenses/by/3.0/). 